\title{
CENTRO INTEGRADO CIUDAD DE LOS POETAS - VALDEZARZA - MADRID
}

Promotor: Gerencia Municipal de Urbanismo del Excmo. Ayuntamiento de Madrid.

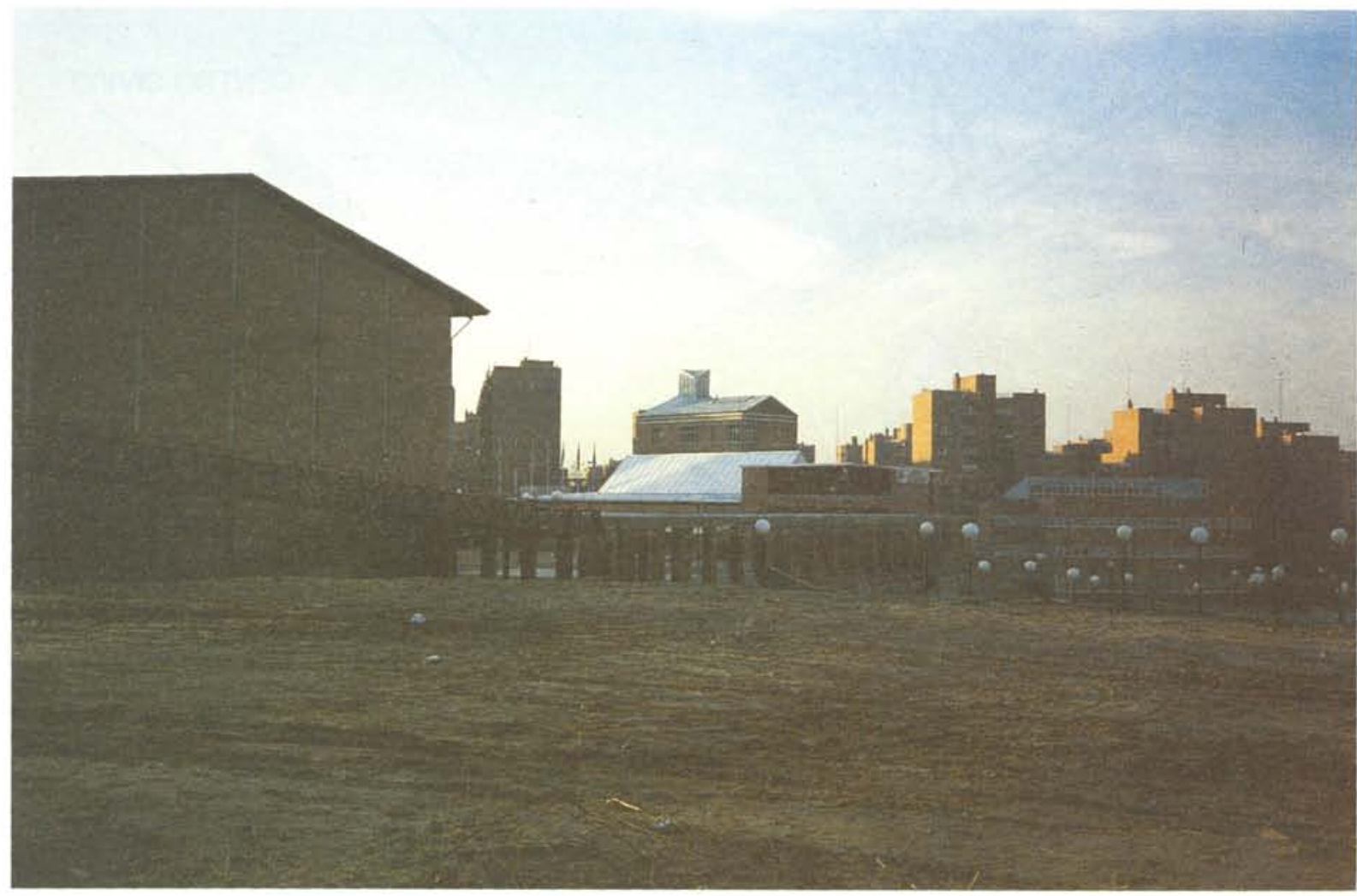

\section{PROYECTOS REDACTADOS:}

- Estudio de Detalle

- Proyecto de Urbanización

- Proyecto de Ejecución de Polideportivo

- Proyecto de Ejecución de Centro Cultural

- Proyecto de Ejecución de Centro de Servicios Sociales

\section{EQUIPO REDACTOR:}

- Arquitectos:

Gabriel Ruiz Cabrero

Enrique Perea Caveda

Esther Sánchez Martinez

Alberto Sepulcre Aguilar

Javier Soto Jiménez

Fernando Diaz Pines

- Cálculo de estructura:

Francisco Jurado Jiménez (Arquitecto)

- Cálculo de instalaciones:

Jesús Extramiana Cameno (Ing. Industrial)
DIRECCION DE OBRA (Gerencia Municipal de Urbanismo):

- Urbanización:

Aurelio Escallada (Ing. de Caminos)

- Edificación:

Rafael Fernández Rañada (Arquitecto)

Eugenio Peña (Aparejador)

REALIZACION DEL PROYECTO: 1985-1986

REALIZACION DE LA OBRA: 1986-1987

EMPRESAS CONSTRUCTORAS:

Urbanización: COMSA

Polideportivo y Centro de Servicios Sociales: EDINHOR, S. A. Centro Civico: FERROVIAL, S. A. 


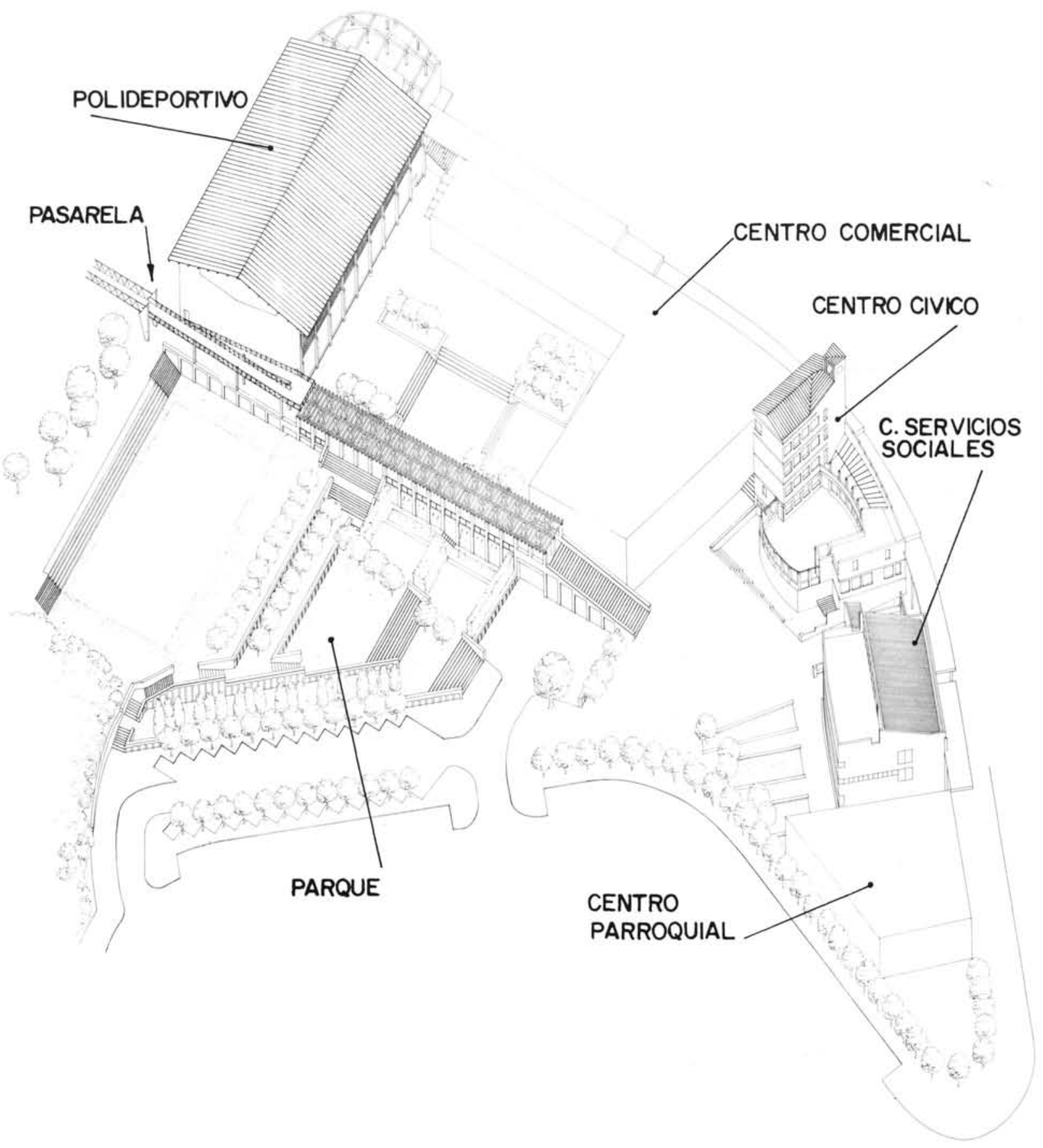

OTROS EDIFICIOS

CENTRO COMERCIAL

Promotor: PACSA Y GEPROCASA

Proyecto y dirección: José Manuel Carrascosa (Arquitecto)

\section{CENTRO RELIGIOSO}

Promotor: Obispado de Madrid

Proyecto y dirección: Jaime Martínez Ramos Carmen Bravo (Arquitectos)

\section{PASARELA PEATONAL SOBRE SINESIO DELGADO}

Promotor: Gerencia Municipal de Urbanismo Proyecto: Gabriel Ruiz Cabrero (Arquitecto) Constructor: COMSA

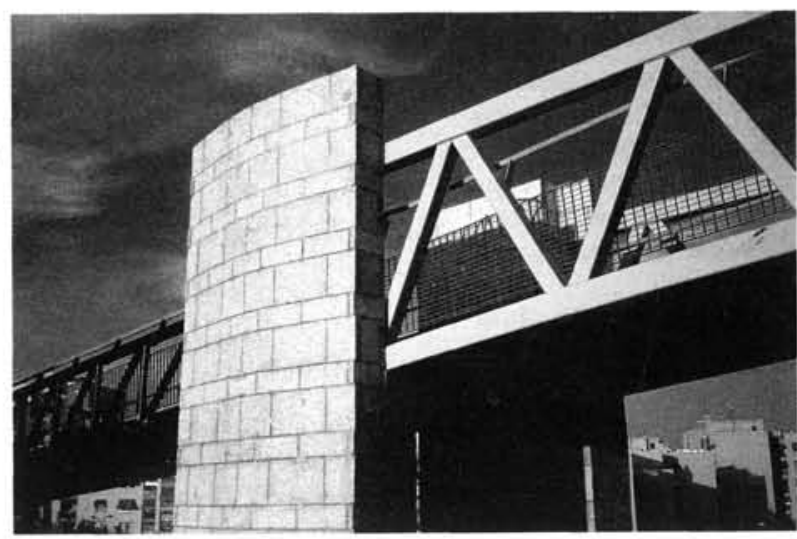




\section{Introducción}

El centro Integrado "Ciudad de los Poetas" - Valdezarza nace de la política del Ayuntamiento de Madrid, para crear dotaciones de barrio en zonas deficitarias, siguiendo las previsiones recogidas en el Plan General de 1985.

\section{Situación}

El solar ocupa una ladera orientada al Norte, en una zona vacia de edificación entre el antiguo barrio de SACONIA, hoy "Ciudad de los Poetas" y el barrio de Valdezarza.

De forma triangular, tiene su frente mayor Oeste hacia la calle Antonio Machado, eje principal del primer barrio, estando limitado hacia el Sur por el futuro eje de Sinesio Delgado, ya en construcción.

Toda la parcela queda rodeada por calles, salvo en su lado Este, donde conecta con un futuro Parque Local. Es toda ella de propiedad Municipal, salvo los terrenos asignados para dotación religiosa en el ángulo más agudo y donde en la actualidad el Obispado está terminando de construir una iglesia.

\section{Objetivos de ordenación}

1) Conseguir el máximo carácter urbano del frente a la calle principal de Antonio Machado.

2) Dotar al área de un espacio cívico de relación, que conecte los barrios existentes, revitalizando la actividad urbana por medio de elementos de clara lec. tura como, pórticos, plazas, paseos, terrazas, escalinatas, pasarelas de peatones, etc.

3) El futuro Parque Local, lindando por el Este, penetra en el Centro Integrado, planteándose una relación de continuidad progresiva.

4) Clarificar el uso del viario perimetral con arreglo a su categoria, adecuando penetraciones y aparcamientos.

5) Facilitar lo más posible, la independencia de construcción y posterior gestión de cada pieza, a pesar del sentido unitario del conjunto.

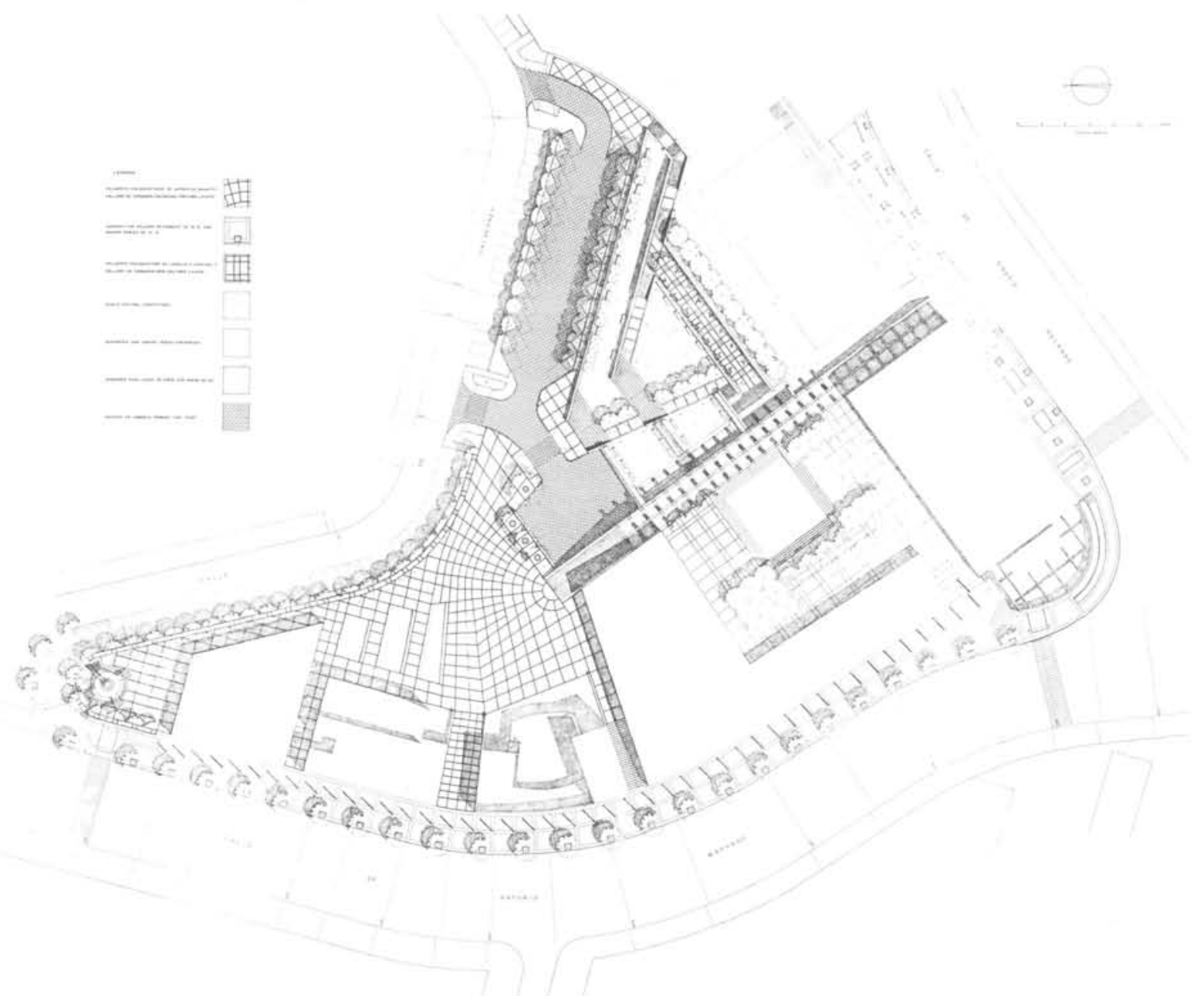




\section{La ordenación propuesta}

Un pórtico potente corre paralelo a la calle Antonio Machado a lo largo de la parcela, adosándose a él todos los edificios y desde donde tienen sus entradas principales. Es el elemento medular del Centro Integrado, imagen tradicional castellana de fuerte carácter urbano.

Estrechos pasos peatonales que parten del pórtico, separando las edificaciones, nos conducen a los dos espacios principales, estructurantes del conjunto, la Plaza Baja y la Plaza Alta. La primera aglutina los usos de carácter cultural y asistencial; espacio totalmente pavimentado con voluntad de ser urbano y flexible de usos, lugar de encuentros y actividades diversas. Una zona de remanso se crea mirando a mediodia, delante del centro de Servicios Sociales. La Plaza Alta, más estancial y ajardinada, queda limitada por el Centro Co. mercial y el Polideportivo.

Una y otra plaza se unen a través de una escalinata que continúa con una pérgola, eje lineal de ordenación del conjunto y circulación principal interior de peato. nes que conecta con la pasarela sobre la calle Sinesio Delgado, para alcanzar los altos del barrio de Valdezarza.

Más hacia el Este, el terreno, de acusada pendiente, se descompone en plataformas ajardinadas con recorridos de escalinatas y paseos solados. Las más altas conectarán con el futuro Parque Local.
El diseño de determinados elementos y de la propia edificación buscan la creación de hitos o referencias singulares del centro: El muro curvo del Polideportivo en la confluencia de Antonio Machado con Sinesio Delgado, la pasarela de peatones sobre esta calle superpuesta en su arranque al testero del Polideportivo, el soportal y la pérgola como elementos lineales, el cuerpo alto del Centro Cívico con su remate en torre del reloj, el volumen cilindrico de la Iglesia en la proa Norte y otra de menor entidad.

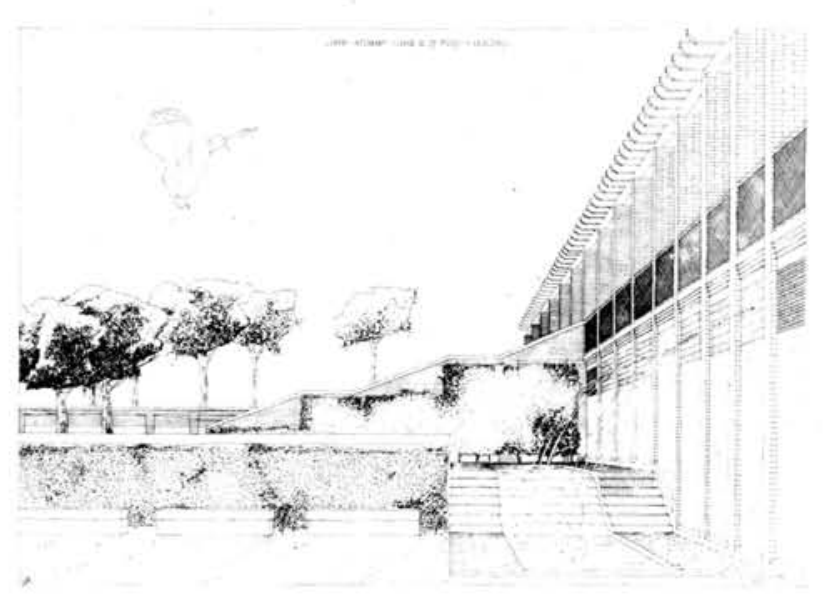

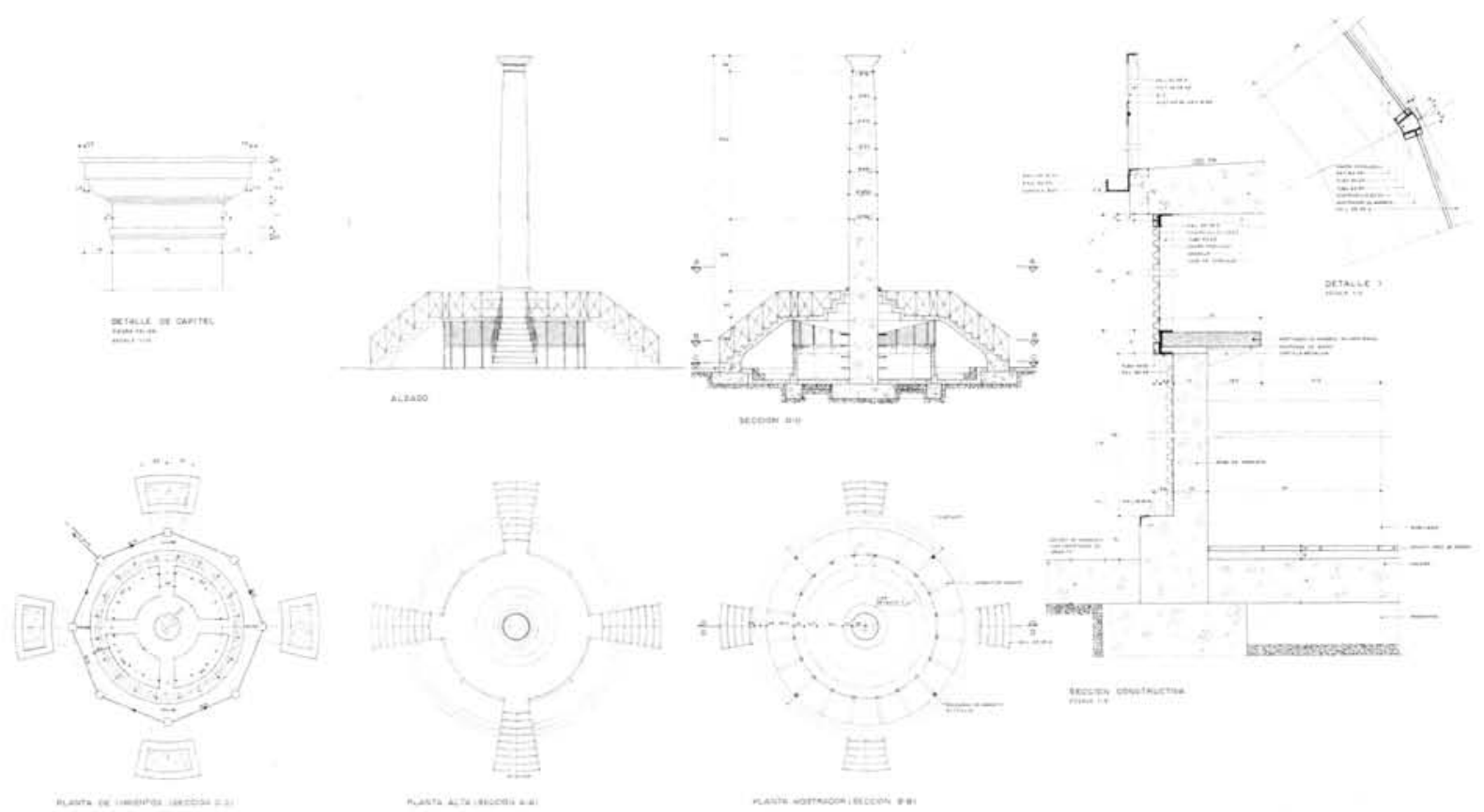



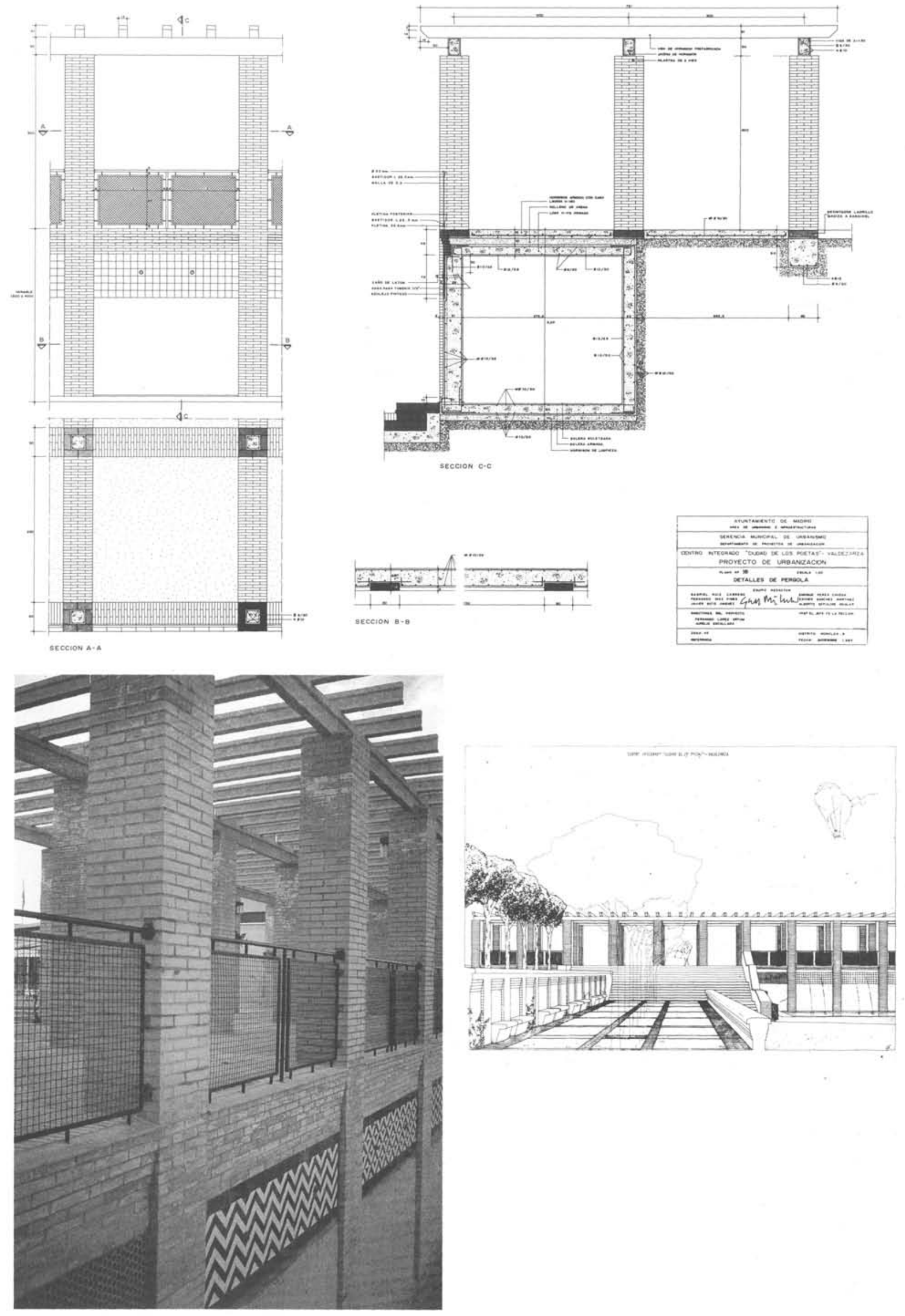

(c) Consejo Superior de Investigaciones Científicas Licencia Creative Commons 3.0 España (by-nc) 


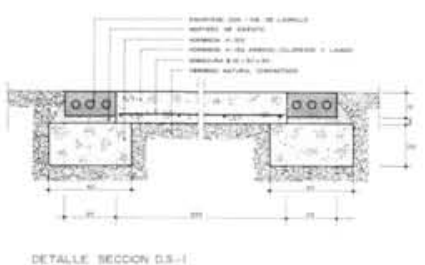

ermain arceon as.
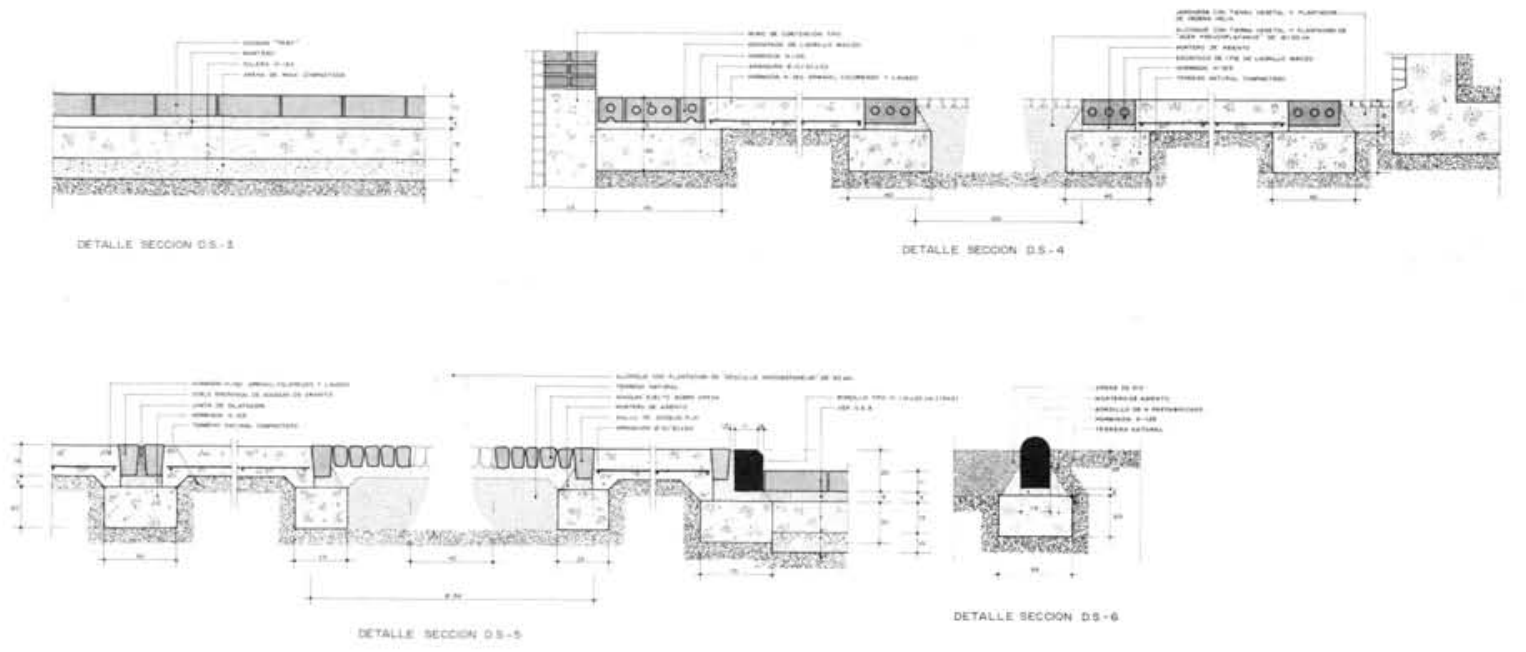

Detalles de la pavimentación del parque.

\section{El Polideportivo}

El programa de este edificio, fuertemente determinado por la superficie máxima definida en el Plan General $\left(1.700 \mathrm{~m}^{2}\right)$ que obligan a un Polideportivo de reducidas dimensiones, ha sido elaborado conjuntamente con el Instituto Municipal de Deportes.

Consta de una pista capaz para futbol sala como deporte de mayor exigencia superficial, vestuarios para dos equipos, árbitros y personal. Botiquín, almacén de material deportivo, dos despachos de monitores, bar, aseos públicos, vestíbulo general y cuarto de instalaciones. Se ha previsto también un mínimo de gradas para público elevadas sobre la pista.

El acceso marca el arranque del pórtico que discurre en todo el frente del Centro Integrado hacia la calle de Antonio Machado.

En el vestibulo general que domina ya la pista, se realiza el control de accesos, más necesario para los usuarios que acceden a los vestuarios de la planta inferior, que para los posibles espectadores.

Todo el programa y su solución se entienden como Polideportivo de barrio, con gran flexibilidad de uso para actividades deportivas o de cualquier otro tipo.

Se ha prestado gran atención a los materiales e instalaciones, buscando durabilidad y mantenimiento mínimo.

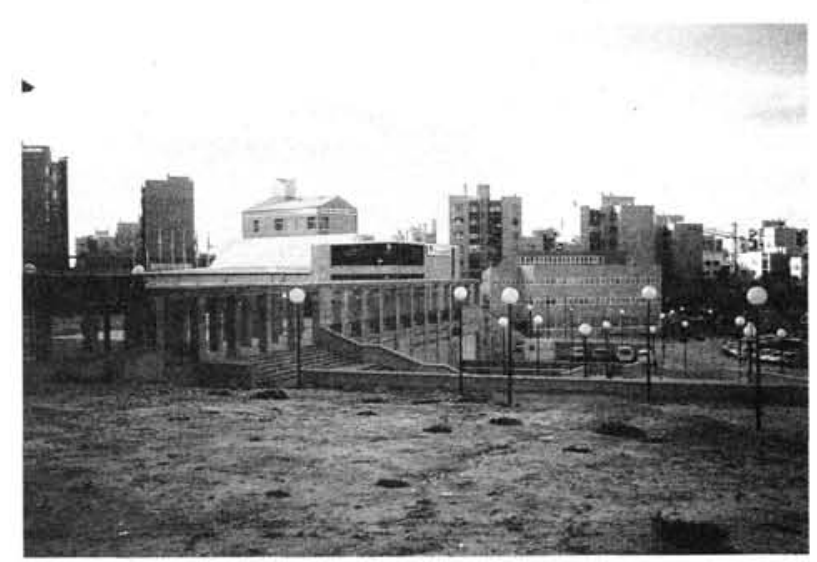

Vista general del parque.

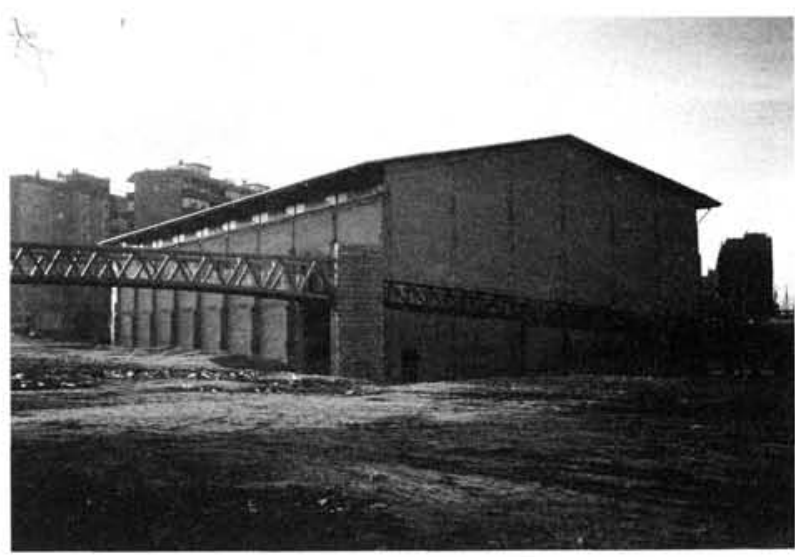

Vista del polideportivo desde la pasarela peatonal. 

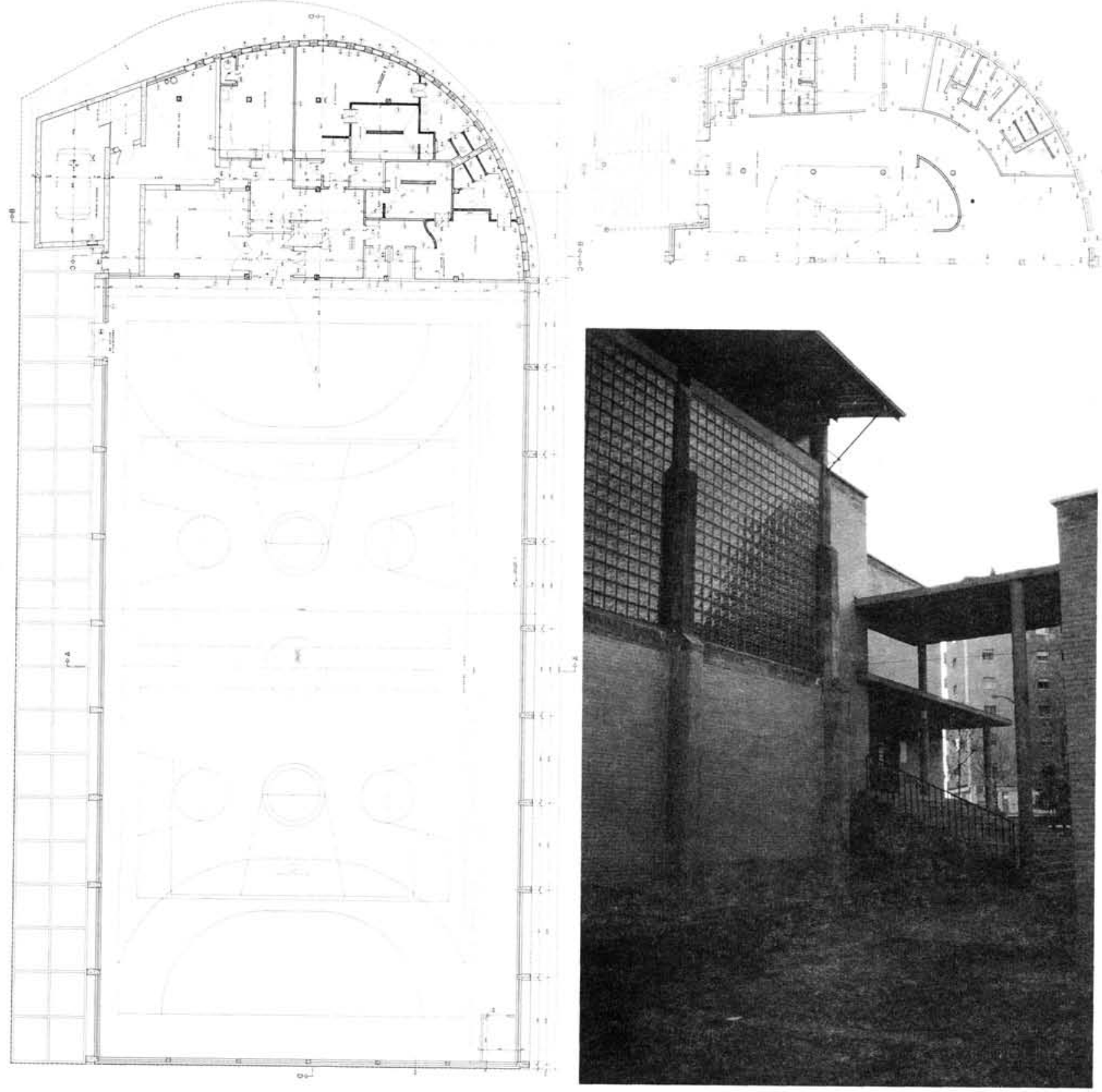

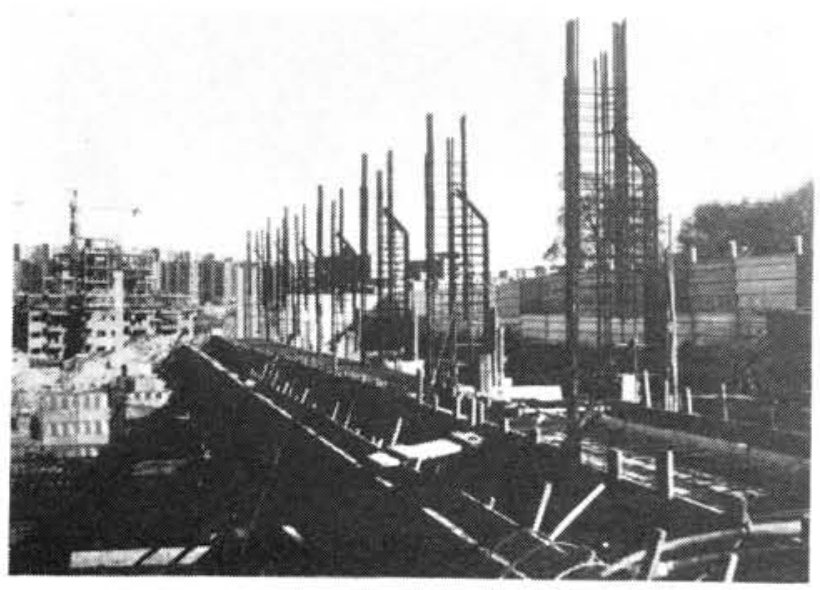

Los soportes en construcción.

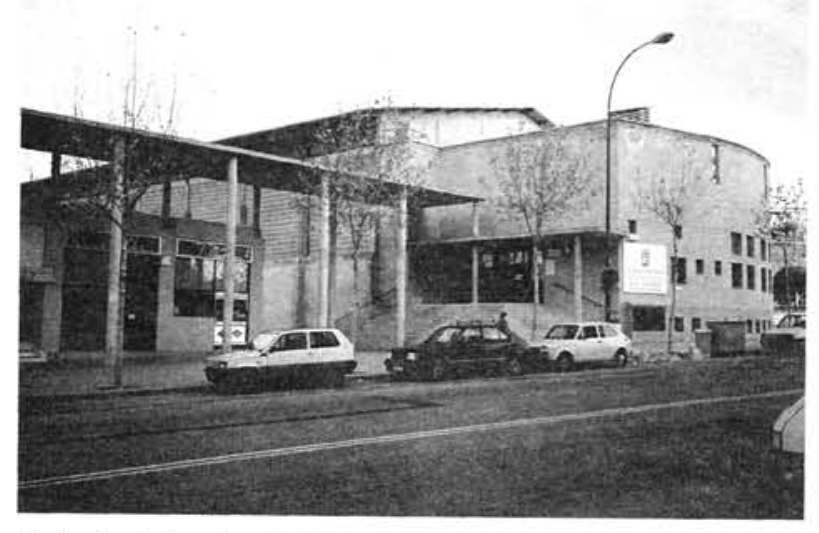

Vista desde la pérgola de acceso. 

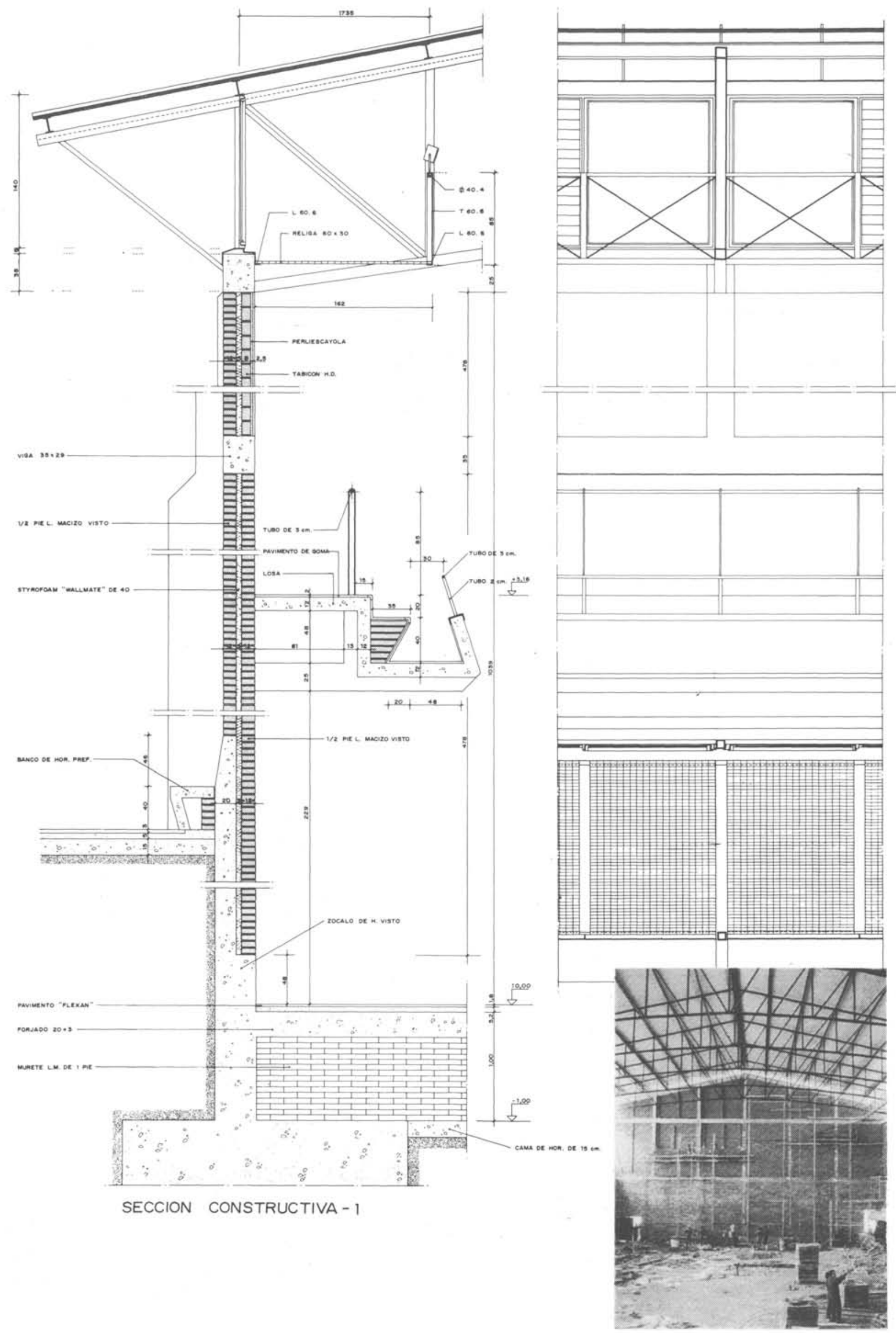

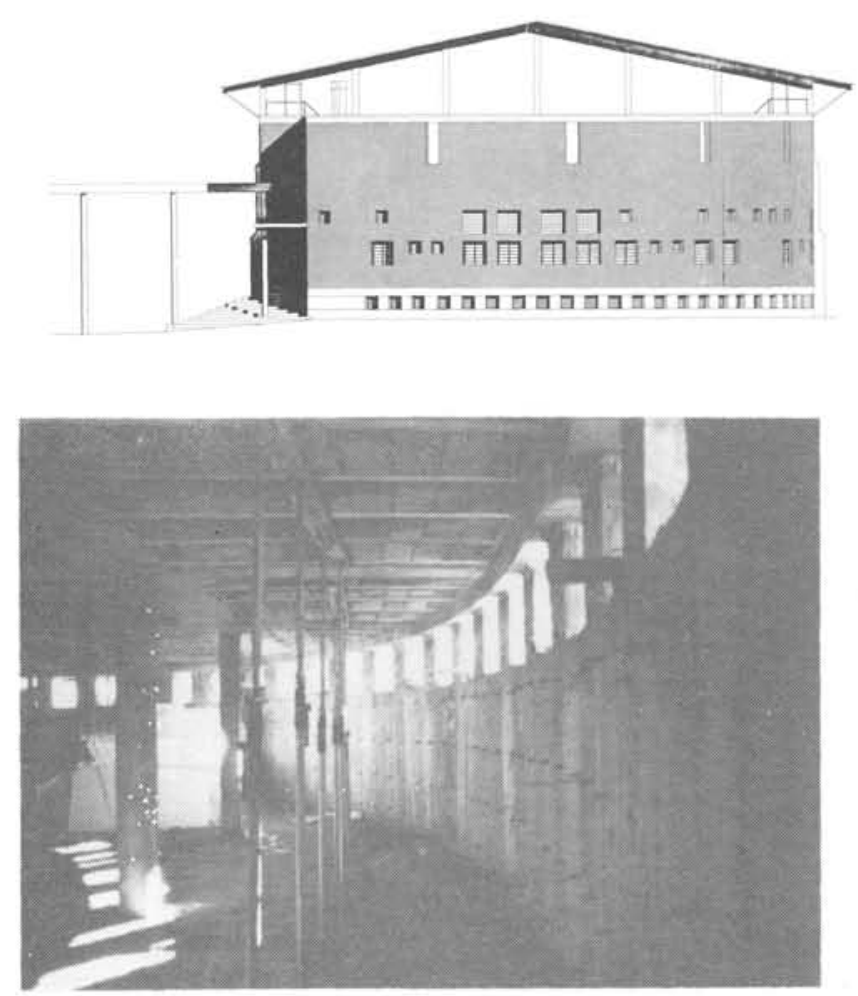

Sotano del polideportivo en construcción.

\section{El Centro Cívico}

Por su situación y diseño en altura pretende ser la cabeza del Centro Integrado.

Se ha considerado condición primordial para la elaboración del programa la flexibilidad, pues resulta difícil prever las demandas culturales del barrio, que tendrán que tener cabida en el edificio, sin más limitación que la superficie máxima fijada por el Plan General y el Estudio de Detalle.

En la Planta semisótano se dispone un pequeño salón de actos con vestibulo para exposiciones comunicado con el vestíbulo principal de planta baja y con acceso también desde la Plaza Baja, taller, aseos generales e instalaciones.

En la Planta Baja, vestíbulo con acceso principal desde el pórtico de la calle Antonio Machado, biblioteca, dirección y aseos. Esta planta se organiza en torno a una terraza exterior como posible lugar de actividades al aire libre dominando la Plaza Baja del Centro.

En plantas superiores se disponen distintos talleres de actividades como música, audiovisuales y como espacio singular abuhardillado con iluminación cenital, el taller de artes plásticas en la última planta.
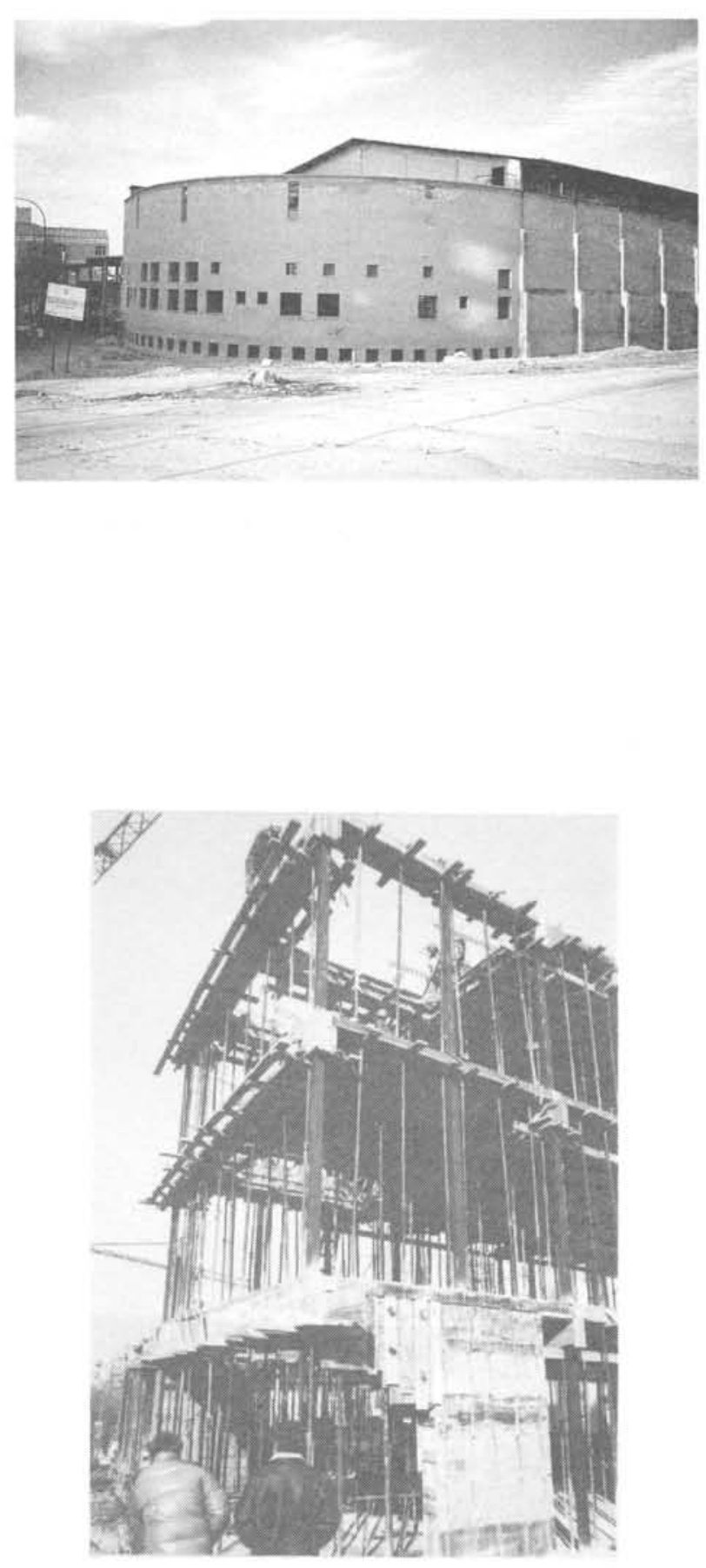

Centro cívico en construcción. 

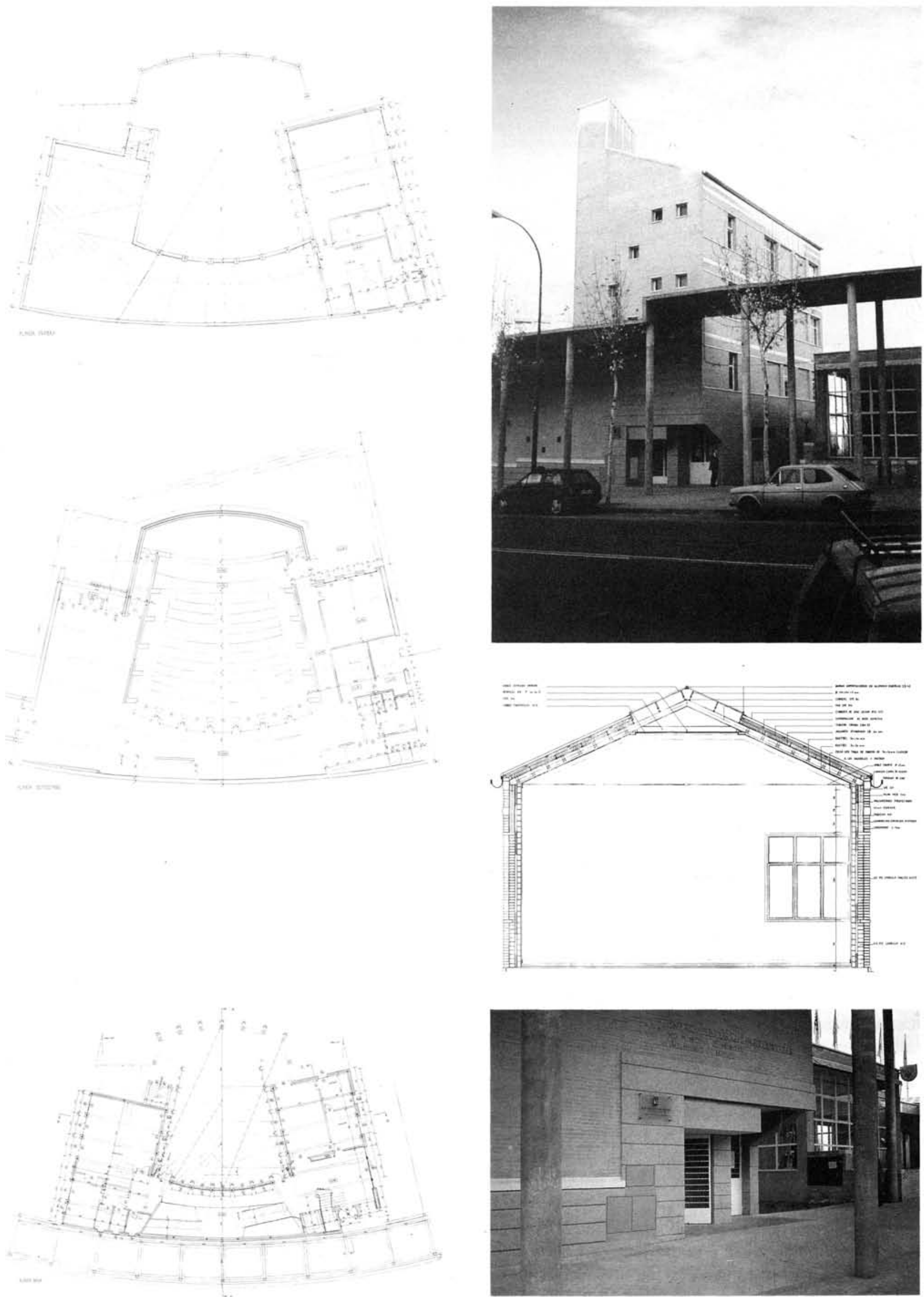


\section{El Centro de Servicios Sociales}

El edificio se descompone en dos cuerpos, uno menor donde se concentran los accesos y otro mayor con las actividades. Los accesos son dos igualmente, conectados entre sí por el vestíbulo general. Uno de ellos, desde la Plaza Baja, da servicio a la gran sala de actividades múltiples (comedor, sala de juegos, reuniones y fiestas, etc.), encontrándose también en esta planta un bar, aseos y toda la zona de servicio con cocina, oficio y lavandería, atendida por una entrada lateral. Un sótano conectado con escalera y plataforma elevado. ra, desahoga esta planta y el resto del edificio con almacenes e instalaciones.

El segundo acceso, principal, se produce desde el pórtico de la calle Antonio Machado, penetrando igualmente al vestíbulo -cuerpo menor de accesos. En esta planta y en la superior se encuentran la dirección al Centro y toda una serie de despachos y salas de reuniones y actividades diversas que se ordenan en torno al perimetro exterior, dejando un espacio interior de relación intercomunicado entre las tres plantas del edificio e iluminado por un gran ventanal superior que se orienta hacia el Este.
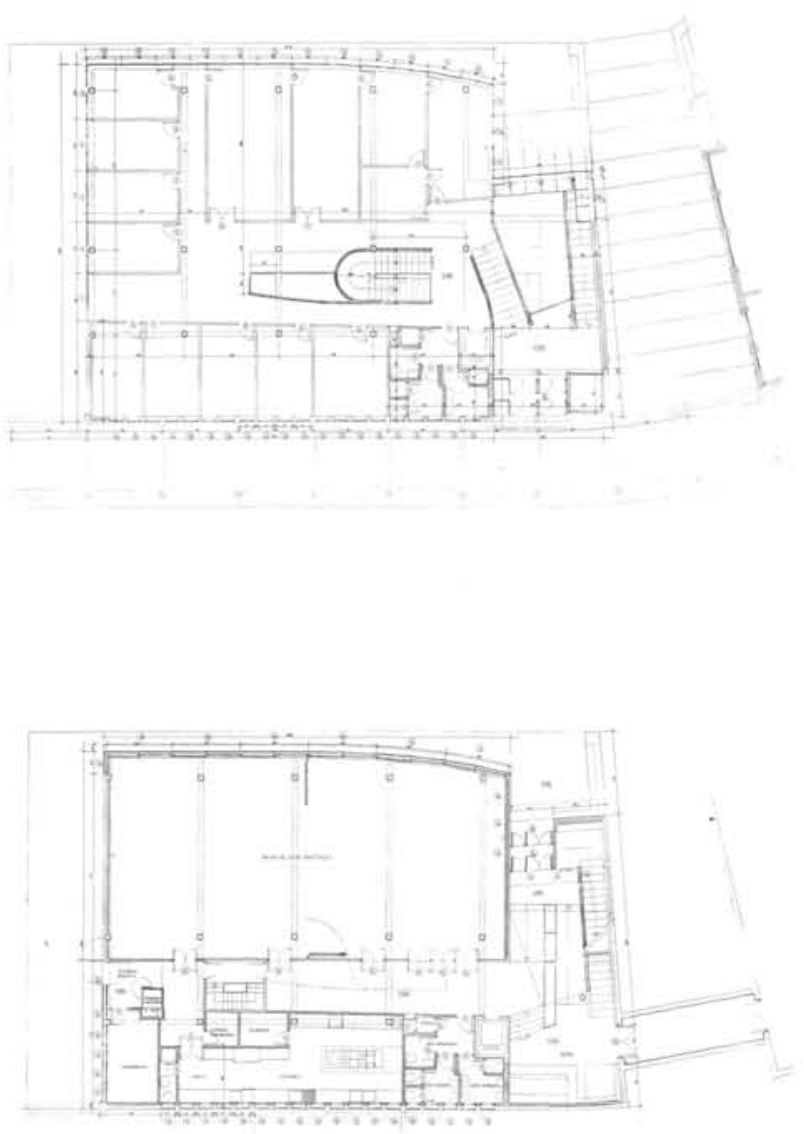

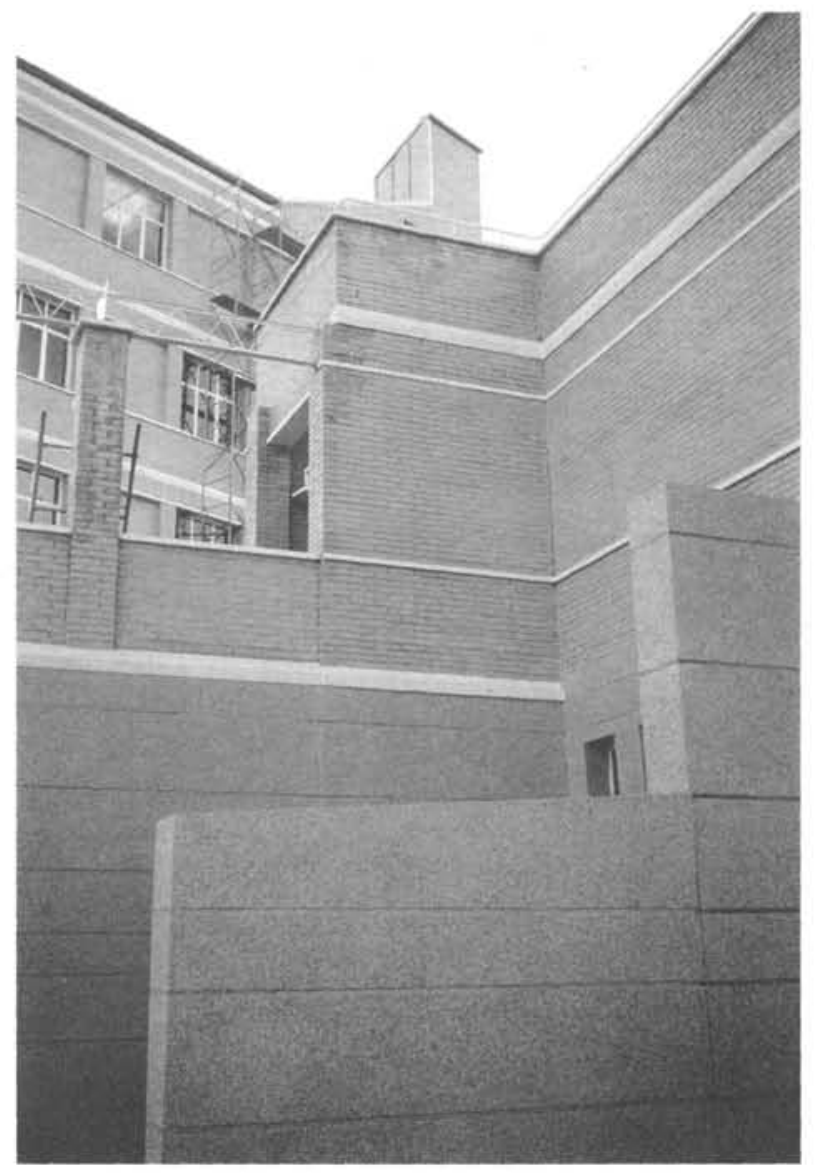

Otra vista exterior del centro civico.
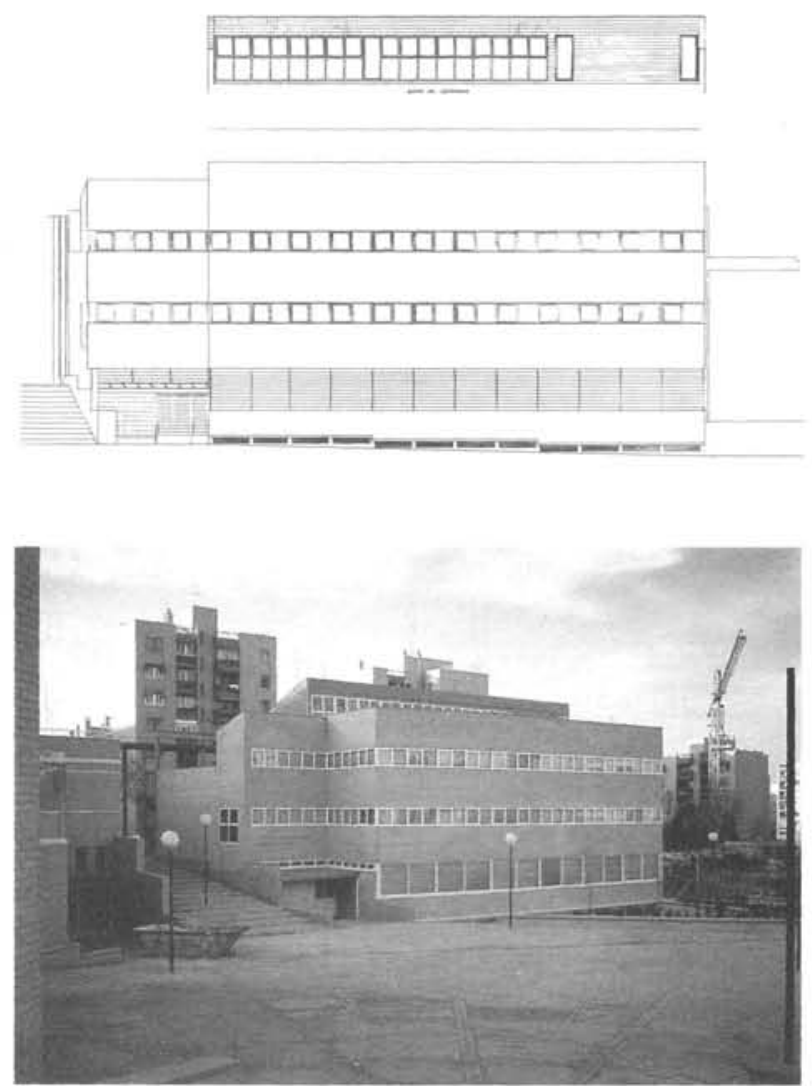


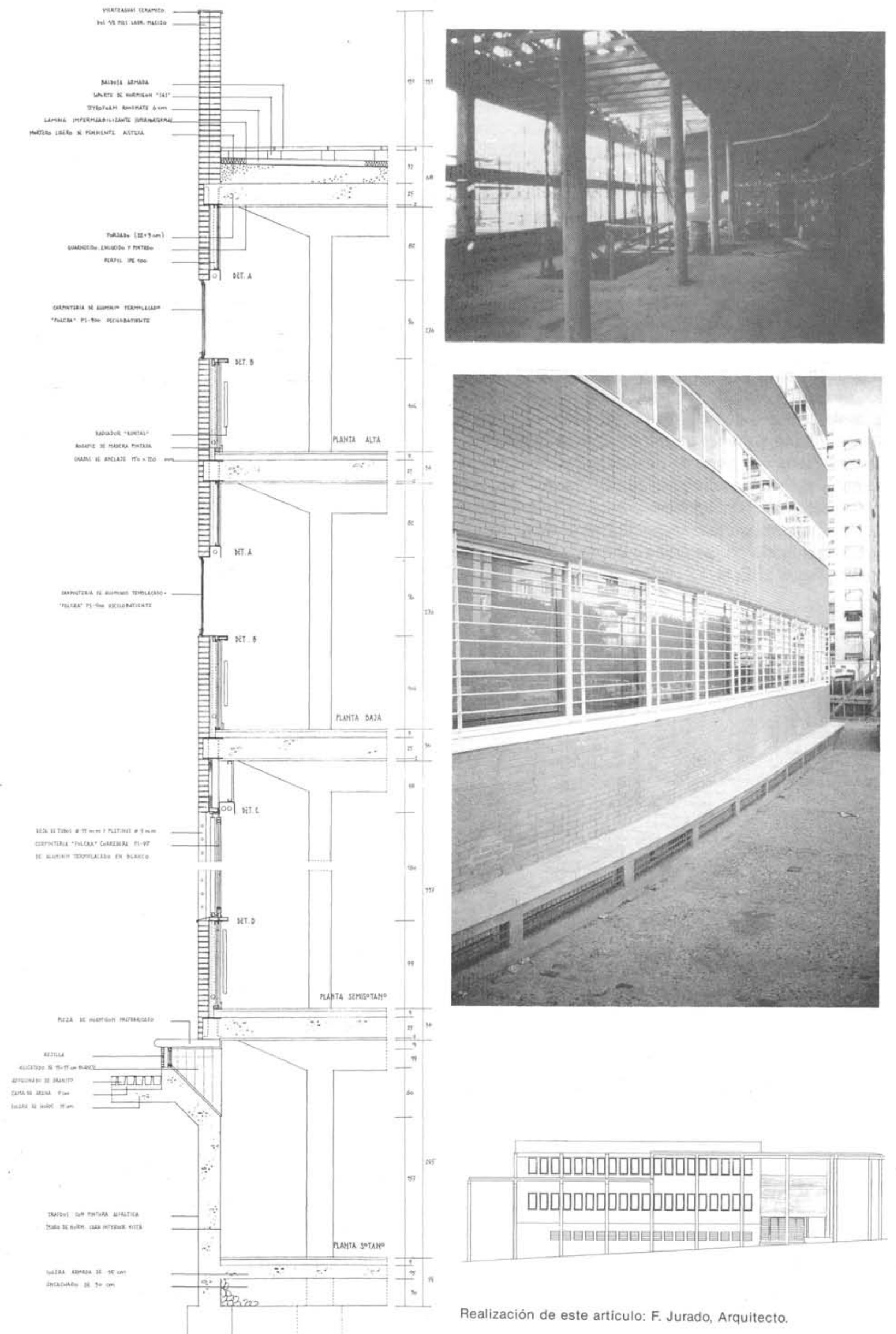

